\title{
A subcontinental view of forest plant invasions
}

\author{
Christopher M. Oswalt', Songlin Fei², Qinfeng Guo³, Basil V. Iannone III², \\ Sonja N. Oswalt', Bryan C. Pijanowski ${ }^{2}$, Kevin M. Potter ${ }^{4}$
}

I US Forest Service, Southern Research Station. Forest Inventory and Analysis. 4700 Old Kingston Pike, Knoxville, TN 37922, USA 2 Purdue University, Department of Forestry and Natural Resources, 715 W. State Street, West Lafayette, IN 47907, USA 3 US Forest Service, Southern Research Station, Eastern Forests Environmental Threat Assessment Center. 200 W.T. Weaver Blvd. Asheville, NC 28804, USA 4 North Carolina State University, Department of Forestry and Environmental Resources. 3041 Cornwallis Road, Research Triangle Park, NC 27709, USA

Corresponding authors: Christopher M. Oswalt (coswalt@fs.fed.us); Songlin Fe (sfei@purdue.edu)

Academic editor: Uwe Starfinger | Received 1 August 2014 | Accepted 19 November 2014 | Published 16 January 2015

Citation: Oswalt CM, Fei S, Guo Q, Iannone III BV, Oswalt SN, Pijanowski BC, Potter KM (2015) A subcontinental view of forest plant invasions. NeoBiota 24: 49-54. doi: 10.3897/neobiota.24.8378

\begin{abstract}
Over the last few decades, considerable attention has focused on small-scale studies of invasive plants and invaded systems. Unfortunately, small scale studies rarely provide comprehensive insight into the complexities of biological invasions at macroscales. Systematic and repeated monitoring of biological invasions at broad scales are rare. In this report, we highlight a unique invasive plant database from the national Forest Inventory and Analysis (FIA) program of the United States Forest Service. We demonstrate the importance and capability of this subcontinental-wide database by showcasing several critical macroscale invasion patterns that have emerged from its initial analysis: (1) large portion of the forests systems (39\%) in the United States are impacted by invasive plants, (2) forests in the eastern United States harbor more invasive species than the western regions, (3) human land-use legacies at regional to national scales may drive large-scale invasion patterns. This accumulated dataset, which continues to grow in temporal richness with repeated measurements, will allow the understanding of invasion patterns and processes at multi-spatial and temporal scales. Such insights are not possible from smaller-scale studies, illustrating the benefit that can be gained by investing in the development of regional to continental-wide invasion monitoring programs elsewhere.
\end{abstract}

\section{Keywords}

Invasive plants, forest ecosystems, macroscale, spatiotemporal patterns

Copyright Christopher M. Oswalt et al. This is an open access article distributed under the terms of the Creative Commons Attribution License (CC BY 4.0), which permits unrestricted use, distribution, and reproduction in any medium, provided the original author and source are credited. 


\section{Introduction}

Exotic invasions can significantly alter the structure, function, and services of ecosystems (Vitousek et al. 1997, Simberloff et al. 2012, Fei et al. 2014). Over the last few decades, considerable attention has focused on small-scale studies of invasive plants and invaded systems. Unfortunately, small scale studies rarely provide comprehensive insight into the complexities of biological invasions at macroscales or across scales (Pauchard and Shea 2006). There is a need for regional to continental-scale invasion data and complementary analyses to facilitate our understanding of scale-dependent phenomena and cross-scale interactions (Soranno and Schimel 2014). Additionally, debate over the detectability of biotic interactions across broad scales (Araújo and Rozenfeld 2014) can only be comprehensively approached through datasets that cross multiple geographic scales. This understanding needs to be incorporated into management plans to ensure the sustainability of vital ecosystem services such as those that are provided by forest ecosystems.

Monitoring plants and animals at a national scale can be difficult and expensive, so databases of this kind are rare. The national Forest Inventory and Analysis (FIA) program in the United States (U.S.) has been monitoring invasive plants (here defined as alien plants whose introduction does or is likely to cause economic or environmental harm or harm to human - see U.S. Executive Order 13112 (1999)) occurrence and spread across all public and private U.S. forests for more than a decade, but to date no attempts have been made to aggregate and analyze data at a national scale. The consistent nature of the FIA sample design (Bechtold and Patterson 2005), and its national sampling intensity of approximately one plot per approximately 2,400 forested hectares (ca. 120,000 total plots), provides a unique view of plant invasions across space and time. The design for FIA inventory plots consists of four $7.3 \mathrm{~m}$ fixed-radius subplots spaced $36.6 \mathrm{~m}$ apart in a triangular arrangement with one subplot in the center (Bechtold and Patterson 2005) that are measured once every 5-7 years in the eastern U.S. and once every 10 years in the western U.S.

The objective of this short communication is to showcase the importance and capability of this unique invasive plant database to encourage its utilization by research and management communities, and to promote the establishment of such large-scale monitoring programs in other regions and continents. To meet these objectives, we present summary results both across the nation and within individual regions to illustrate how such a program can produce new insights into invasion ecology and the potential drivers of invasions that are not possible from smallerscale investigations.

Due to the considerable number of invasive plants in the U.S., data are collected based on region-specific monitoring lists of problematic forest plant invaders agreed upon by invasive plant experts (Oswalt et al 2012). We extracted invasive plant data from the FIA program and calculated summary statistics for each region, as well as across the entire nation. As invasive plants of concern differ by region and, in some cases, by state, we normalized the data to be able to characterize nation-wide patterns using an invasion-intensity metric. Normalization was achieved by calculating 


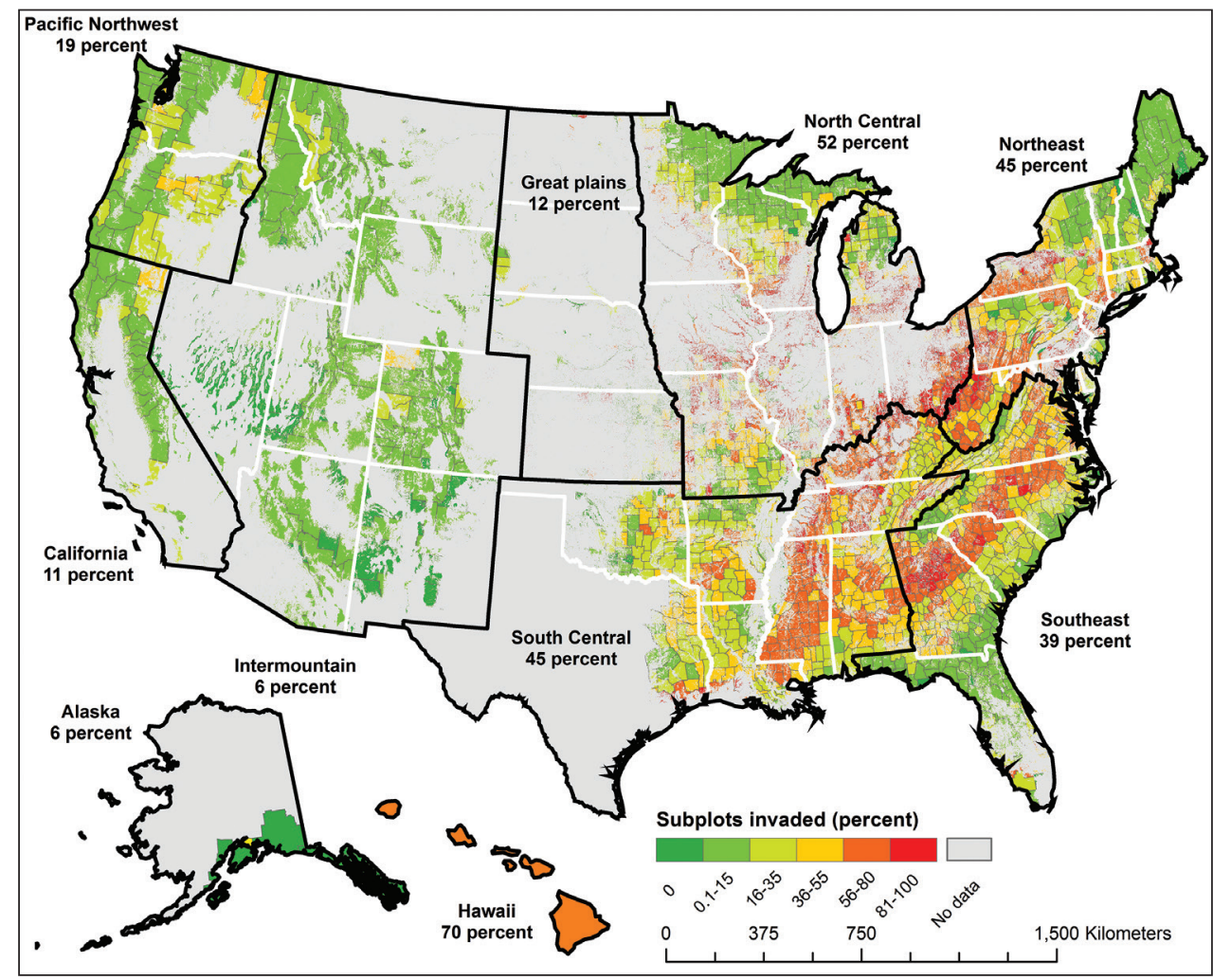

Figure I. Forest plant invasion intensity (percent of forested plots with an invasive plant recorded for a given county based on FIA sampling) for the United States including estimates of region-wide invasion intensity.

the number of forested subplots with at least one invasive species present in a given county divided by the total number of forested subplots monitored in the same county. Therefore, we define invasion-intensity as the percent of forested subplots within a county containing any invasive plants that are on the region/state-specific monitoring lists. We then mapped the subcontinental spatial distribution of invasive plants based on this invasion-intensity metric. In addition, we mapped the expansion of Imperata cylindrilca to showcase the capability of the database in studying the temporal dynamic of invasive plants.

We observed multiple macroscale invasion patterns based on our simple initial analyses that would not have been detectable from smaller scale studies, highlighting the utility of national-level sampling efforts. First, 39\% of forested plots sampled nationwide for invasive plants contained at least one invasive species, revealing that a significant portion of the more than 300 million hectares of U.S. forests have been invaded. Clearly, the footprint of invasives is significant at large scales. Hawaii had the highest invasion-intensity (70\%). Second, forests in the eastern U.S. had higher invasion-intensity $(46 \%)$ than in the west $(11 \%)$, while forests in Alaska (6\%) and the Intermountain region $(6 \%)$ had the lowest invasion intensity (Figure 1). Third, 
Table I. Top five most inventoried forest invasive plants by the FIA program within each region of the United States.

\begin{tabular}{c|c|c|c|c}
\hline Rank & South & North & Intermountain West & Pacific \\
\hline $\mathbf{1}$ & Lonicera japonica & Rosa multiflora & Bromus tectorum & Bromus tectorum \\
\hline $\mathbf{2}$ & Ligustrum sinense/vulgare & Phalaris arundinacea & Cirsium arvense & Rubus armeniacus \\
\hline $\mathbf{3}$ & Rosa spp. & Alliaria petiolata & Centaurea biebersteinii & Hypericum perforatum \\
\hline $\mathbf{4}$ & Lespedeza cuneata & Lonicera japonica & Cynoglossum officinale & Cirisium arvense \\
\hline $\mathbf{5}$ & Microstegium vimineum & Rhamnus cathartica & Carduus nutans & Taeniatherum caput-medusae \\
\hline
\end{tabular}

clusters of more highly invaded counties may suggest a strong relationship between invasion intensity and human land-use legacies at regional to national scales. Specifically, highly fragmented landscapes (as in the North Central region) and major travel corridors (as in the Piedmont of the Southeast) tended to exhibit higher invasionintensity (Figure 1). In addition, we observed variability in invasion patterns across both climate regimes and elevation gradients suggesting further investigations into how climate change could facilitate or impede future invasions are needed.

The dataset also revealed it will be important to understand what factors have driven the expansion of the most prevalent invaders in forest ecosystems, such as Rosa multiflora in the north, Lonicera japonica in the south, and Bromus tectorum in the Intermountain and Pacific regions (Table 1). The same is true for invaders that are currently quickly expanding, such as the expansion of Imperata cylindrica from an epicenter located near Mobile Bay (Figure 2) in the southern U.S. At fine scales, repeatedly measured FIA plots will allow for investigating the drivers of such expansions. The accumulated dataset, which continues to grow in temporal richness, with its inclusion of multiple measurements of the same plots will allow researchers to reveal temporal invasion patterns and processes at large spatial scales.

As other large-scale datasets (e.g., climate, elevation, land cover, soils, human population and natural resource management practices, etc.) become more readily available, we can conduct more comprehensive investigations into ecologically and economically important questions such as: What are the underlying processes that produce the macroscale invasion patterns and how do these processes differ and/or interact across scales? What are the traits of both invaders and invaded ecosystems that facilitate invasion? And what are the cross-scale interactions that lead to the emergence of macroscale patterns such as those observed in this report? Integration of these data and other invasive taxonomic groups, such as insects, birds, and mammals, could provide macrosystems ecologists with broader "systems" perspective of invasive ecology.

While these data aid the development of a more comprehensive understanding of plant invasions within forests of the United States, there were challenges to assembling them in their current form and obstacles to their analytical use. To harmonize the data, several normalizations had to be performed and some comparability across regional boundaries at finer scales was lost. Nonetheless, no comparable dataset exists, and the macroscale invasion patterns that have emerged from even the relatively simple analysis of this dataset clearly reveals the benefit of large-scale invasion monitoring program. 


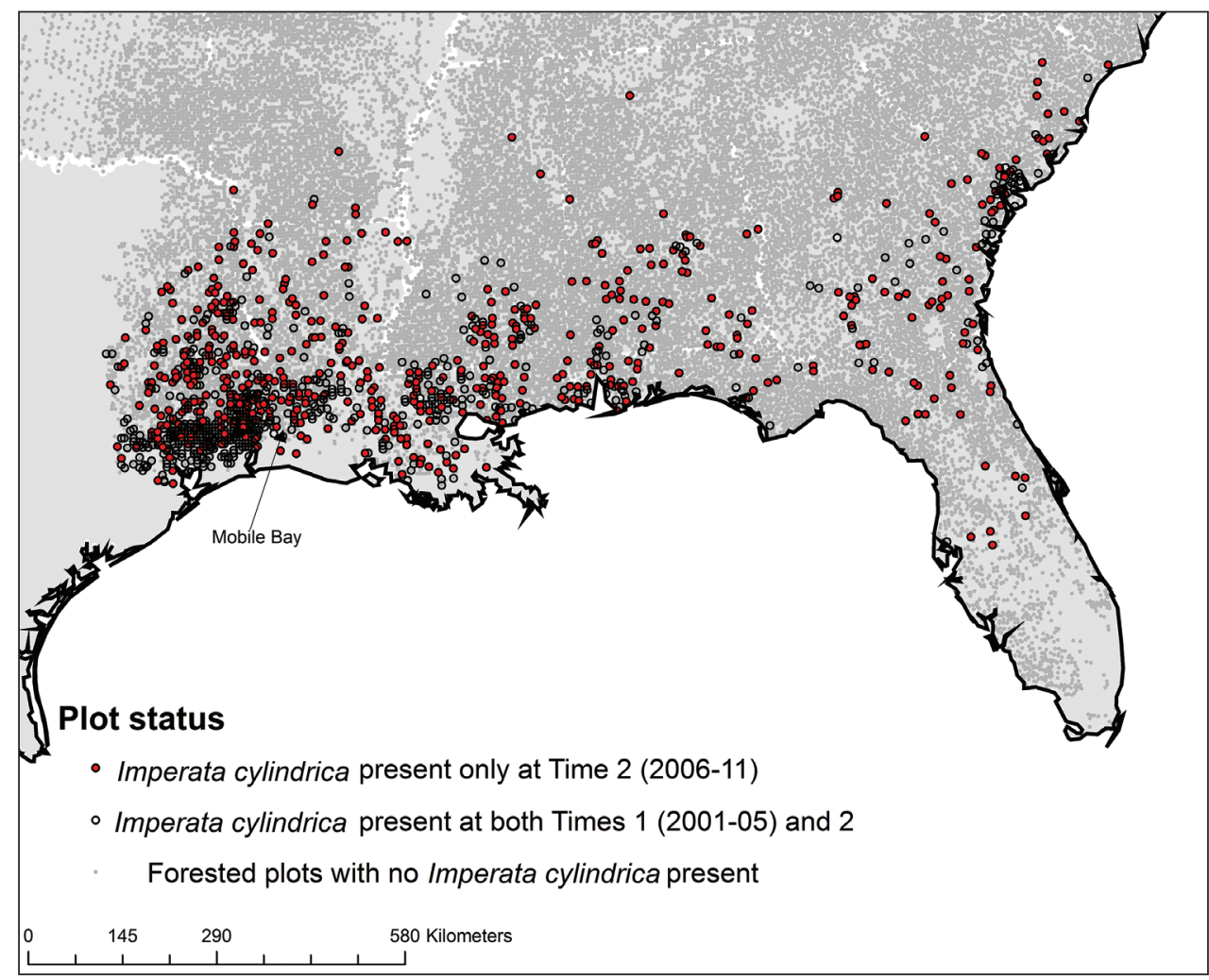

Figure 2. Spatial progression of Imperata cylindrica based on multiple measurements of forested plots from the FIA sampling grid. Time 1 represents data collected from 2001 to 2005 and Time 2 from 2006 to 2011.

\section{Acknowledgements}

The data presented here were collected by numerous hard-working individuals throughout the United States, and we thank them for their tireless efforts to document the presence of invasive plants on our nation's forests. Additionally, we are grateful to Keith Moser, Cassandra Kurtz, Beth Schulz, Christopher Witt, and Andrew Gray for assembling the data from their respective regions. This research was partially supported by the National Science Foundation (grant \# 1241932).

\section{References}

Araújo MB, Rozenfeld A (2014) The geographic scaling of biotic interactions. Ecography 37: 406-415.

Bechtold WA, Patterson PL (2005) The enhanced forest inventory and analysis program: national sampling design and estimation procedures. US Department of Agriculture Forest Service, Southern Research Station. 
Fei S, Phillips J, Shouse M (2014) Biogeomorphic impacts of invasive species. Annual Reviews of Ecology, Evolution, and Systematics 45: 69-87. doi: 10.1146/annurev-ecolsys-120213-091928

Oswalt C, Oswalt S, Zimmerman L (2012) Updating the southern nonnative plant watch list: the future of NNIP Monitoring in the south. In: Morin R, Liknes G (Eds) Moving from status to trends: Forest Inventory and Analysis (FIA) symposium 2012; 2012 December 4-6; Baltimore, MD. Gen. Tech. Rep. NRS-P-105. US Department of Agriculture, Forest Service, Northern Research Station, Newtown Square, PA, 274-277. [CD-ROM]

Pauchard A, Shea K (2006) Integrating the study of non-native plant invasions across spatial scales. Biological Invasions 8: 399-413. doi: 10.1007/s10530-005-6419-8

Simberloff D, Martin J-L, Genovesi P, Maris V, Wardle DA, Aronson J, Courchamp F, Galil B, García-Berthou E, Pascal M, Pyšek P, Sousa R, Tabacchi E, Vila M (2012) Impacts of biological invasions: what's what and the way forward. Trends in Ecology and Evolution 28: 58-66. doi: 10.1016/j.tree.2012.07.013

Soranno PA, Schimel DS (2014) Macrosystems ecology: big data, big ecology. Frontiers in Ecology and the Environment 12: 3-3. doi: 10.1890/1540-9295-12.1.3

Vitousek PM, Aber JD, Howarth RW, Likens GE, Matson PA, Schindler DW, Schlesinger WH, Tilman DG (1997) Human alteration of the global nitrogen cycle: sources and consequences. Ecological Applications 7:737-750. 